\title{
Formation of Modern Musician's Personality in Educational Environment of Higher Education Institution: Complex Approach
}

\author{
Natalia Anufrieva ${ }^{1}$, Eugeny Anufriev ${ }^{1}$, Irina Korsakova ${ }^{1}$, Irina Slutskaya ${ }^{1} \&$ Anna Sherbakova ${ }^{1}$ \\ ${ }^{1}$ Russian State Social University, Moscow, Russian Federation \\ Correspondence: Natalia Anufrieva, Russian State Social University, Wilhelm Pieck str., 4, Moscow, 129226, \\ Russian Federation.
}

Received: October 31, 2014

Accepted: October 31, 2014 Online Published: February 25, 2015

doi:10.5539/ass.v11n6p13

URL: http://dx.doi.org/10.5539/ass.v11n6p13

\begin{abstract}
This article proves the necessity of a complex approach to the formation of the personality of the musician in a modern higher education institution of musical-pedagogical orientation. This approach is due, above all, harmonious nature of the man himself, that combines the moral qualities, cognitive ability, aesthetic taste, communicative orientation, desire for creativity, as well as the huge potential of musical art in the education of the comprehensive person, having the ability to implement the deep essence of the human utpada, maintain and transmit it through space and time. The complex approach is holistic, value-meaning equality of all participants in the educational process of professional activity, the unity of requirements to the content, methods and organizational forms of education.
\end{abstract}

Keywords: music, education, personality spiritual formation, complex approach, professional training of teacher-musician, educational environment

\section{Introduction}

Scholars characterize the beginning of the third millennium as a crossroads, a moment of man's choice of his way in order to preserve life on Earth. Once again, we turn to the eternal questions, the range of which was formulated by P. Gurevich in his seminal work "The Man Philosophy". These issues are now in the period of acute crisis of civilization sound especially important. "What is Man? Can we consider him as a unique creation on the Earth? What is the nature of Man? What determines sovereignty of his spirit? What is the drama of human relationships and human existence? What influences the meaning and value of human life? To what and where is the person go in the course of his historical development? Why is the end of the next millennium associated with persistently apocalyptic forebodings?" (Gurevich, 1999).

The range of topics is added with more and more issues. Is further human existence possible on the planet Earth? Is there a place for art in the cultural space of the twenty-first century? Does art have any role in the life of today's man? Does he need music or is her role exhausted as well as the historical mission of humanity? For modern researcher, answers to these questions are very important because the problem of self-realization and self-actualization in the cultural space is directly linked with the comprehension of the place and role of music in life and activity of modern man. Today, relevance of opinion expressed by O. Apraksina is obvious, the need to understand the role of music in society life, the importance of musical education in an encyclical creative development of personality, the techniques and methods of such education cannot be kept unchanged since living conditions are permanently changing (Apraksina, 1983). "Music is a constantly developing dynamic world, able to advance, foresee, anticipate phenomena that are only approaching and are about to happen in the society. This is a world, possessing such a strong intuition and creative imagination that it is able to make the most unexpected turns which cannot be analyzed by linear intellection", A. I. Scherbakova thinks (Shcherbakova, 2013).

The emergence in the cultural space of Homo Musikus, creator of sounding being space, is one of the amazing mysteries, which attracted the attention of researchers through the centuries. So Toropova, musician, psychologist, asks: "What is "Homo Musicus" in the semantic translation, rather than transcription? Is it a musical man, or a person who plays music, a person who sounds ("like a cymbal") or a person $<\ldots>$ who intonates, who is expressing something in the world for himself and for others $<\ldots>$ All these are functional sense facets of a single human nature, that has different lights in different cultural and scientific contexts. Inside or at the intersection of these faces, there is a person generating and generated with musical symbol genesis, a person 
with musical consciousness, or some consciousness, ensuring continuity of sound symbol genesis." (Toropova, 2008).

The need to create a musical and educational space as artistic and aesthetic integrity of the organization is determined by the terms of the development of the internal space of a future musician, in which training tradition and innovation are in the structure of its discrete units: knowledge, categories, orientations and behavior. This requires the creation of "fields" of creativity in an integrative educational environment of the higher education institution, as well as research and social practice of students as well as taking into account their individual characteristics (Shishova, 2014).

The main principles for the development of the creative personality, intellectual and emotional wealth of the person in each of the age levels were methodologically grounded in the Concept of Education Development in the Field of Culture and Art in 2008-2015 (Russian Federation Government Decree, 2008), which gave the music-educational community the ability to simulate a professional musical education space in the perspective, where the freedom of the future expert's choice is based on the preference of the moral behavior regulators, and the existing and attainable goals of the student-musician's intellectual, spiritual and professional development are classified as strategic objectives, which correspond to the list of systemically important features: the system composition (combination of different elements); structure (interaction variability between the system elements); operation (dynamic system state, determined by the common goals implementation technology). During higher education preparation, it is not so much important to reveal the specifics of music as a special kind of art, which "construction material" is sound, and not to try to see the whole picture of the music world, it would be a mockery to "embrace the unembraceable", but it is important to send creative thought to "spirit sphere" in order to, as B. Tselkovnikova said, “... go out into the space of Thought and Spirit," which ... helps it to understand the diverse and wise face of Being" (Tselkovnikov, 1998).

\section{Methods}

Complex methodology to the process of professional training of the student musician is determined, ultimately, with his awareness of himself as an integral part of human culture, which takes place through the understanding of the nature and value of the culture phenomenon. Professional training of musician based on the complex approach to the artistic and scientific knowledge of the artistic culture involves a holistic, value-meaning equality of all participants in the learning process, reflecting the characteristics of professional activity of the future musician and defining the general requirements to content, methods and organizational forms of education.

Therefore, semantic, essential aspects of the university educational environment, which determines the personal and social educational values, ideals, and behaviors of students-musicians, are set by a meaningful level of global, national culture. At this intersection point of the social and the cultural, a new meaning and a new quality of education are born, which are not contained in each of these concepts, considered in isolation from each other.

The problem of holistic education and upbringing of the individual, its personal identification is revealed in social space with the need to develop cultural environment values by the younger generation of musicians, as well as cultural norms for preserving of social sustainability and stability, transferred in inextricable link from generation to generation, which perception and reproduction cause his/her moral and creative self-development. The future musicians' cultural diversity development in the complex, which combines different types and genres of art, can be seen as a process of creating their own spiritual space, harmonious relationship with the world and themselves, achievement of personal identification. A. I. Scherbakova believes that "Àrt in general and music as one of the most amazing species, allow a person to discover the uniqueness of his inner world, to grasp the essence of human nature, to marvel at its immensity" (Tselkovnikov, 1998).

Essential characteristic of the complex approach is the holistic interaction of intellectual, emotional and volitional, as well as personal qualities of the future musicians, such as freedom, tolerance, responsibility, and others. Humanistic basis of a constructive approach to the process of the students' professional skills formation assumes formed national cultural accentuation significantly actualizing the student's personal formations, such as values and meanings attitude to the various forms of future practice: artistic and creative, pedagogical, cultural and educational, research, and others.

\section{Results}

Priorities for the development of national culture are seen as summarized concepts of professional polyartistic education in modern Russia. It should be understood as follows: first, a focus on the learning of panhuman, universal development component of modern science, cultural achievements of modern man and humanity, their 
respective acquisitions in the past. Second, a focus of the graduate on the organic coherence with life national-cultural foundations of his people and state, which will allow him to participate fully in the modern dialogue of cultures, the reproduction of his national ethic community's culture. Third, integrating component of the cultural and centric working on a personal level that is a culture of a young musician's individual activities in all spheres of life in society, a culture of the organization of his individual development, a culture of thinking, reflection and creation of his world, the surrounding reality.

This context implies an active process of the graduate's personal development in accordance with modern standards of education in the society, which will promote the development of deep structures of the individual in various areas of future professional activity: the development of the graduate's social skills and social activity; professional skills formation required for understanding and implementing of various practice types (performing, cultural and educational, research, etc.); the communication skills formation and development required to manage the interaction with the social environment; "Self-concept" formation, self-awareness as an active subject for the various types of professional activities; understanding of his social roles in a multicultural artistic and educational space, and others. (Music is basic to human design. Even so, musical experiences of any kind are shaped not only by sonic interactions within particular sociocultural contexts, but also by individual subjectivity, maturation, and individual life-events) (Graham, 2012).

In the first decade of the XXI century, the system of higher humanitarian vocational education gets a new look, which is determined by the specific socio-economic conditions, the state of science, technology, culture, environment, the specific dimensions of artistic and creative activity of people. "On the threshold of the XXI century in a series of panhuman values, the man himself is pushed, G. A. Praslova points out, that is the basis for bringing of anthropological knowledge to the study of educational events in the past and, in particular, in the history of music education, considering it from the point of the personality essential powers implementation" (Praslova, 2006).

Determinants in this direction are the terms of the academic community of higher education institutions, teachers and students. Today, Russian pedagogical space is focused on providing artistic and aesthetic unit of the national culture as its core curriculum. Artistic direction vocational by means of musical art transmits the accumulated musical and creative experience from previous generations to the following, contributes to the enrichment of the individual's spiritual world.

\section{Discussion}

In sermon "Walk with the Spirit" N. Kuzansky (Nicholas Krebs, a German theologian and philosopher), whose life and work belongs to the distant past (XV century), still was unaware of such concepts as "systematic way of thinking", "synergy", "complex approach", very aptly and accurately expressed the idea of the man, his spiritual essence, as the integrity consisting of "the identical and the different", that is a sometimes "mass of contradictions" that causes a person to reside in a state of reflection (Kuzansky, 1981).

Thinking of the spiritual life of man, its relationship with the outside world, its self-sustaining nature, the fifteenth century's philosopher reaches out to our contemporaries, revealing to him the deep essence of being grasped through music. He says: "Picking up the monochord, a skilled musician wrests an octave from the same string at the same numerical proportions, with a different ratio, he wrests a quart, even when new - fifth; and they form all the other harmony. In this case, the musician does not reach anything in this art other than consistent with his own nature. After all, he would not know the reason why it is necessary to call as the harmony the ratio of one to two (an octave) or two to three (fifth), if he did not find in these sounds kind of harmony with the fact that he carries within himself and what he is, and if he did not hate dissonance, wildest with his own essence. In himself, he has a measure and by this measure he measures, calculates, matches, and separates, deploying in the musical signs the things that he holds inside himself" (Kuzansky, 1979).

In his sermon, N. Kuzansky not only formulated the essence of man as a complex structural, self-sustaining and self-tuning holistic system, not only revealed through the music of the creative interaction principle in the chain of Man and World, but also clearly demonstrated that the art of music is originally humanistic, since it is a hidden human essence in the musical signs, expressing only that "he carries inside himself and what he is", "holds inside himself", seeks to convey through time and space as personal knowledge, experience.

Thus, the spiritual formation of the individual is a gradual, systematic and purposeful process, in which the desire to understand, to comprehend the uniqueness of his own "Ego" and at the same time to determine the degree of relatedness of the "Ego" with the outside world, that is, to find the possibility of a harmonious existence in it. Postmaterialist spiritual psychology includes the view that consciousness is the fundamental strata of all surrounding reality, of which our human mind is part and parcel (Miller, 2012). It allows us to be 
constantly reminded of the importance "personal identity" or "self-identity" problems. The researchers emphasize that "the basis of this identity feeling or state is formed similarity in worldview, values, traditions and way of life. This feeling is generated in comparison of "their" and "foreign" and, of course, this "foreign" influences on their own perception" (Davies, 2011).

Turning to the problem of personal identity closely related to human needs, personal and value aspirations, seeing the world, the American philosopher Erich Fromm identifies the following aspects: the need for communication in inter-individual bonds, without which a person loses social skills and cultural standards; the need for creativity as a deep human intentions dictated by the presence of the creative powers in each individual; the need to sense the deep roots, to feel himself as a certain link in a stable chain of the human race; the pursuit of knowledge and the development of the world; desire for likening, search of sample, ideal that the person wants to be like, that is, the desire for cultural identity (Fromm, 2004). To be means to give expression to all inclinations, talents and gifts, which reside in each of us, writes philosopher (Fromm, 2009).

Let us analyze each of these aspects in order to determine their relevance to the undertaken research. The main problem of our study is music, the art facing directly away from the heart to the heart, which the most important function is the social-communicative. In music, this need for communication in inter-individual bonds is expressed very clearly. It closes up the certain social skills (social code, in the terminology of T. Adorno (2014)), it carries with it both cultural standards, developed over the centuries. "The thought embodied in the sound is the living expression of feeling arising in the process of the world understanding, so it becomes the basis not only for knowledge, but also for self-knowledge", A. I. Scherbakova thinks (Shcherbakova, 2012). Therefore, the first aspect, highlighted by Erich Fromm, is originally founded in the art of music and, accordingly, it must be present in the musical education process. The second aspect is the need for creativity as deep human intentions, dictated by the presence of the creative powers in each individual, is greatly manifested in the creation of music, and in the process of understanding it. The third aspect is the need for a sense of deep roots, the need to feel him as a certain link in a stable chain of the human race, and this is one of the main directions of the undertaken research. And all the other aspects, including the pursuit of knowledge and development of the world, the pursuit of likening, the search of sample, ideal, which the person wants to look like, that is, the desire for cultural identity, are fully consistent with the goals and objectives put forward in this article.

Speaking about the formation of personality, there are several components necessary for the complex harmonious development:

- Moral and ethical component that is implemented in the outlook and includes moral and ethical standards, aspirations, life goals, beliefs;

- Aesthetic component, determined by the need for consumption and the creation of beauty, the pursuit of perfect;

- Cognitive component that provides productivity of cognitive activity and includes volume and number of the assimilated information;

- Communicative component, implemented in a variety of roles that a person plays in society and is determined by qualities such as sociability, in-touch capability, mutual understanding and respect;

- Creative component is a comprehensive feature of the personality, determined by the ability and capacity for productive action.

Suzanne B. Hanser considers that while an entire group of people are engaged in a musical activity, no two are expressing themselves in precisely the same way. Thus, it provides a format for learning about one's own unique manner of approaching the creative process, expressing one's self, interacting with others, and organizing and interpreting artistic material (Hanser, 2005).

All these components of personality are developed and improved in the learning process, and the task of the teacher is to contribute to the formation of various aspects of the personality, his/her self-consciousness, spirituality and culture, initiative, independence, tolerance, the ability to successful socialization in society and active adaptation to the labor market.

Consideration of musical and educational environment as complex self-developing system requires from teachers to students the formation of persistent interest in the cognitive process, instilling in students the ability to observe, compare, analyze, model, classify and summarize the knowledge gained in the content of certain disciplines according to the state educational standards, educational plans for specialty and direction of their professional training. 
And it is extremely important that the Russian science defines, as an essential aspect of personal identification, the cultural and ethnic identity, which is not only formed in the process of personality formation, but also laid down in the genotype of a person, his mentality. Of course, ethnicity is a part of an overall social identity and significantly affects its formation and functioning, because the basis of the formation and functioning is the certain socio-psychological patterns.

\section{Conclusion}

To summarize, we can say that modern man needs spiritual guidance to facilitate the cultural development logic comprehension; in the study of the mechanisms that determine one or another scenario of society cultural development; in national and personal identity, deter sense of belonging to the country culture and respect for other cultures; in creating the conditions for a positive attitude and opportunities for value comprehension and semi-creative transformation (modeling of the world, according to M. Kagan (1997)) of socio-cultural space of our time.

To solve these problems is necessary to form a system of values, allowing the younger generation of musicians to navigate directly within the experienced here-and-now present, which is defined as a socio-cultural space of the third millennium. Therefore, higher professional school training specialists in education, culture and art, identified as one of the main objectives training of graduates who are competitive in the labor market, have formed values and positive qualities of awareness of national cultural and historical heritage, willingness to interact with dialogicality with culture of peoples and ethnic groups of the region, the country, and others. Hence the conclusion that the main criterion for the quality of music students' learning is not only a high level of professional competence, functional training to perform certain types of professional activity, but also the development of personal qualities that allow them to be adaptive, competitive, stating and achieving goals through self-realization, self-education, improving themselves and their surroundings, having a tolerant attitude to the representatives of the various ethnic communities.

Important way of optimization of musical and artistic education is a complex approach to the formation process of musician personality as a whole, the organization of educational environment targeting influence, which is based on the idea of unity and general musical knowledge, defining further successful acquirement of the mastery fundamentals.

Need to study and scientific understanding of the updating of the modern pedagogical university system based on the complex approach is due to the increasing requirements to the musicians' training level to improve the quality of vocational education in the high schools of culture and art. Studying the culture and art graduates' personality formation mechanisms involves the relationship of systemic organization of his future professional activities. This relationship is expressed in the following parameters:

- Completeness of development and self-determination of the musician is formed at latitude of range and content of future professional activity;

- Quality of the training and education of a professional musician is mediated by the activity and communication: the organization of the educational process, self-education, self-organization, self-management, etc.;

- Formation issues of a holistic culture based on the humanization of education and upbringing of the musician personality, an upward trend of his development as a system and a social institution;

- Personal culture formation of the future musician in a rapidly changing social and cultural situation in the society.

To solve this problem, it is necessary to create a holistic educational environment, which actually operates on the basis of student's independent choice and independently developed cultural norms and aims to provide the conditions for the assimilation of cultural values on the basis of creative activity. Music and educational environment of higher education institution is to provide the conditions for the musician's personal development realization in any sphere of professional activity: arts and culture, general and additional musical education, social services, and others. They are to be defined in state educational standards of professions and areas in arts, culture and education.

\section{References}

Adorno, T. (2014). Favorites: The Sociology of music. M: Centre for humanitarian initiatives: University book, $445 \mathrm{~S}$.

Apraksina, O. A. (1983). Methodology of musical education in school (p. 222). M.: Education.

Fromm, E. (2004). Escape from Freedom (p. 318). M.: AST Publisher. 
Fromm, E. (2009). To have or to be (pp. 138-139). TRANS. from English. E. Telyatnikov. Moscow AST.

Graham, F. (2012). Welch and Gary E. McPherson. Introduction and Commentary: Music Education and the Role of Music in People's Lives. In G. E. McPherson, \& G. F. Welch (Eds.), The Oxford Handbook of Music Education (Vol. 1).

Gurevich, P. S. (1999). The man Philosophy (p. 221). M.: IP of RAS.

Hanser, S. B. (2005). The New Music Therapist's Handbook (2nd ed., p. 142). Retrieved from

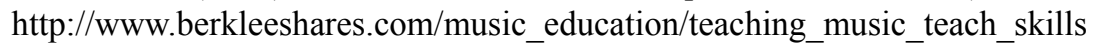

Kagan, M. S. (1997). Philosophical theory of value (p. 203). SPb.: Petrópolis.

Kuzansky, N. O. (1979). On the Beauty (p. 295). Aesthetics \& Life. Rel. 6-Common Aesthetics Problems. M.: Iskusstvo.

Lisa, J. M. (2012). The Oxford Handbook of Psychology and Spirituality.

Nicholas, K. (1981). Science ignorance. Fool for wisdom. "Thou art all fair, my love". Walk in the spirit. Translation and introduction centuries bibikhin. Fragments. In B. N. Shestakov (Eds.), Aesthetics of the Renaissance: An anthology in 2 volumes (pp. 109-138).

Praslova, G. A. (2006). Relationship between tradition and innovation in musical-pedagogical education. Innovations, 2, 83-94.

Russian Federation Government Decree. (2008). Concept of the Education Development in the Field of Culture and Art in 2008-2015. Retrieved August 21, 2014, from http://www.artexplorer.ru/

Shcherbakova, A. I. (2012). Philosophical glance at music and musical education in the art expanse of the contemporary culture: Historical and cultural aspect. Social Policy and Sociology: Interdisciplinary theoretical and practical magazine, 12(90), 117-135.

Shcherbakova, A. I. (2013). An individual in understanding sounding space of objective reality: Experience of social and philosophical analysis. Signum Temporis, 1(6), 25-37.

Shcherbakova, A. I. (2014). Philosophical understanding of music as a methodological basis of research in the field of musical art and education. Life Science Journal, 11(11), 429-432.

Shishova, E. (2014). Peculiarities of person's speech and thought activity in the context of multicultural education. Middle-East Journal of Scientific Research, 19(9), 1137-1141.

Stephen, D. (2011). Musical Understandings and Other Essays on the Philosophy of Music.

Toropova, A. V. (2008). HOMO-MUSIKUS in the mirror of musical-psychological and musical-pedagogical anthropology (p. 288). M.: Educational-methodical publishing center "GRAPH PRESS".

Tselkovnikov, B. M. (1998). Music teachers in the space of Thought and Spirit: Reader (p. 126). M.: Text.

\section{Copyrights}

Copyright for this article is retained by the author(s), with first publication rights granted to the journal.

This is an open-access article distributed under the terms and conditions of the Creative Commons Attribution license (http://creativecommons.org/licenses/by/3.0/). 